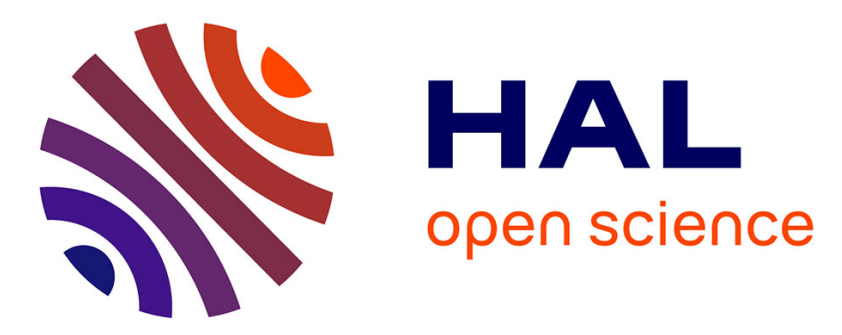

\title{
Defect creation and development at the polysilicon-silicon interface during a cold technology simulation
}

\author{
C. Jourdan, J. Gastaldi, M. Bienfait
}

\section{- To cite this version:}

C. Jourdan, J. Gastaldi, M. Bienfait. Defect creation and development at the polysilicon-silicon interface during a cold technology simulation. Revue de Physique Appliquée, 1984, 19 (11), pp.941943. 10.1051/rphysap:019840019011094100 . jpa-00245287

\section{HAL Id: jpa-00245287 https://hal.science/jpa-00245287}

Submitted on 1 Jan 1984

HAL is a multi-disciplinary open access archive for the deposit and dissemination of scientific research documents, whether they are published or not. The documents may come from teaching and research institutions in France or abroad, or from public or private research centers.
L'archive ouverte pluridisciplinaire HAL, est destinée au dépôt et à la diffusion de documents scientifiques de niveau recherche, publiés ou non, émanant des établissements d'enseignement et de recherche français ou étrangers, des laboratoires publics ou privés. 


\title{
Defect creation and development at the polysilicon-silicon interface during a cold technology simulation
}

\author{
C. Jourdan (*), J. Gastaldi (*) and M. Bienfait (**) \\ Campus de Luminy, 13288 Marseille Cedex, France
}

(Reçu le 16 mai 1984, accepté le 31 juillet 1984)

\begin{abstract}
Résumé. - La topographie de rayons $\mathrm{X}$ est utilisée pour analyser les diverses étapes de fabrication d'un composant lors de la simulation d'une technologie froide $\left(<950^{\circ} \mathrm{C}\right)$. On montre que, d'abord, une déformation élastique apparaît juste à l'aplomb de la bordure des motifs. Ensuite, des défauts ponctuels sont créés, sous oxydation, à l'interface silicium-silicium polycristallin. Enfin, on observe une dégradation de la qualité cristalline de la plaquette quand les traitements chimiques et thermiques sont poursuivis.
\end{abstract}

\begin{abstract}
A simulation of a cold technology $\left(<950^{\circ} \mathrm{C}\right)$ has been analysed by X-ray topography at different stages of its elaboration. It is shown first that an elastic deformation occurs straight below the edges of the film pattern. Then, point defects are generated at the polysilicon-silicon interface upon oxidation. Finally the crystalline quality is perturbed in the whole bulk wafer upon further chemical and heat treatments.
\end{abstract}

\section{Introduction.}

The deposition of a thin film of polycrystalline silicon on the wafer back surface is a new method $[1,2]$ used to getter metals from silicon devices. This technique is compatible with most integrated circuit processing schemes and has the advantage that it does not induce deformation in the wafer. Accordingly, it is tempting to check whether this new gettering process improves the performances of solid state devices. As part of this ambitious project, we studied the creation and the development of defects in a silicon wafer at different stages of a process of cold technology $\left(<950^{\circ} \mathrm{C}\right)$ performed by the LETI-CEA (Grenoble). The final goal is to correlate the defect evolution and density to lifetime measurements and optimize the physicochemical and heat treatments during device fabrication. In this paper, we only report our observation of defects by X-ray topography at different sequences of the simulation of the process, leaving to a more complete article the detailed presentation of the relationship between the structural and electrical properties of the manufactured devices.

\section{Experimental.}

The starting material is commercially available wafers with $\sim 1 \mu \mathrm{m}$ polycrystalline silicon deposited at the

(*) CRMC ${ }^{2}$-CNRS.

(**) Equipe de recherche associée au CNRS-Département de Physique. backside (Monsanto). A thin silicon oxide layer $(\sim 100 \AA)$ called « pedestal » is first deposited on the wafer surfaces. The geometry of the sample is sketched in part I of figure 1. Then, about $700 \AA$ of silicon nitride is deposited on both sides and a photolithographic process is used to fabricate $\mathrm{Si}_{3} \mathrm{~N}_{4}+\mathrm{SiO}_{2}$
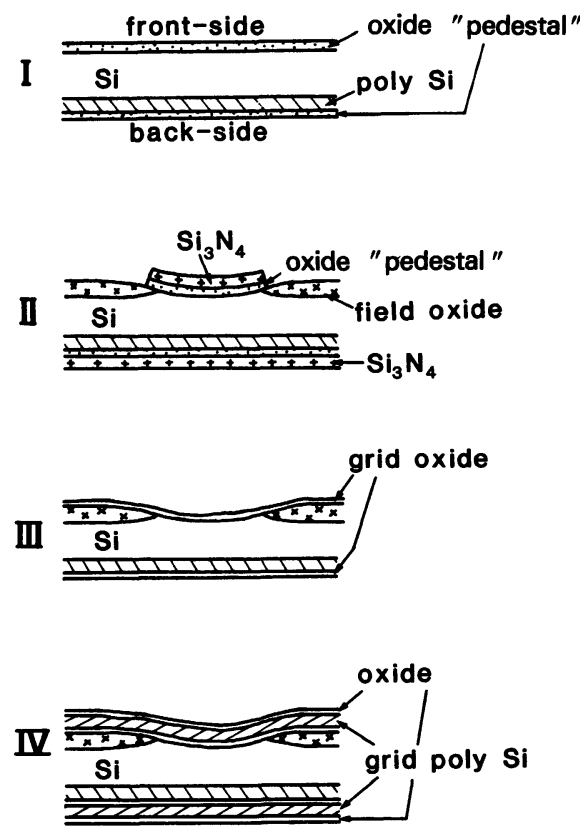

Fig. 1. - Sketches of the different stages of the process simulation (see text). The thicknesses of the deposited materials are not at the right scale. 
" pedestal " patterns at the front side. After that a wet oxidation is carried out and results in the formation of $\sim 4000 \AA$ of oxide on the non-protected parts of the surface. The obtained structure is represented in part II of figure 1 . In the next step, $\mathrm{Si}_{3} \mathrm{~N}_{4}+$ $\mathrm{SiO}_{2}$ " pedestal » film patterns are removed and a $\sim 300 \AA$ grid oxide is grown. This corresponds to the drawing III in figure 1 . Then, polycrystalline silicon is deposited, annealed and partly oxidized. The final structure is sketched in IV.

At each stage I, II, III, IV, the silicon crystal quality is observed by X-ray topography. Figure 2 represents the principle of the recording. A fine, parallel X-ray beam probes a section of the wafer under a Bragg incidence. The diffracted image is recorded on a photographic plate. If a crystallographic defect $\mathrm{A}$ is located along the path of the incident beam, the

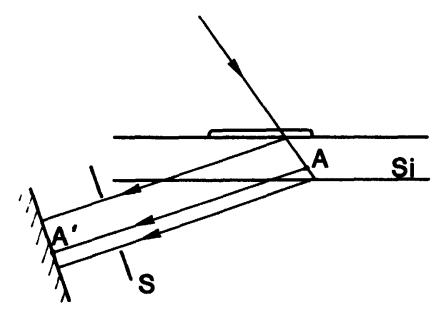

Fig. 2. - Principle of X-ray topography.

local variation of the Bragg condition induces a modification of the image contrast in $\mathrm{A}^{\prime}$. Hence, the topography of the crystal defects can be explored section after section by moving the crystal (and the plate) with respect to the incident beam. Furthermore, if a region of the sample is too strongly perturbed and yields too intense a scattering, the slot $S$ can be used to reduce the probed part of the section. This capability is illustrated in figures $3 b$ and $c$. In that case, the film pattern at the front surface introduces a strong perturbation of the scattered beam (Fig. 3b). To obtain a better resolution in the topography of the Si crystal section, one can intercept the beam scattered from the front surface by acting on the slot. The obtained topogram is presented in figures $3 \mathrm{c}$. Finally, if the X-ray incident beam sweeps continuously the wafer surface, the images of the sections are superimposed on the photographic plate. As a result, one gets a projection of all the defects contained in the wafer. This is illustrated in the topographs of figures $3 \mathrm{a}$.

\section{Results.}

The evolution of the defects in the wafers after the various treatments described in figure 1 is shown in the X-ray topographs presented in figure 3. Step I exhibits no defects within the instrumental resolution $(\sim 5 \mu \mathrm{m})$ as seen on both projection (Ia) and section (Ib). The good quality of the crystal is confirmed on the section by the enhancement of the diffracted intensity at the surfaces and by the occurrence of Pendellösung fringes.

On stage II, the deformation of the wafer by the $\mathrm{Si}_{3} \mathrm{~N}_{4}+\mathrm{SiO}_{2}$ film pattern is visible in projection IIa. This deformation is located at the edge of the pattern [3]. Only the part of the stress for which the diffraction criterion g.b is different from zero, are revealed in figure $3 \mathrm{Ila}$. If the $2 \overline{2} 0$ reflection had been used instead of the 220 ones, another set of contrasts perpendicular to the preceding ones would have appeared. Except for these localized deformations, no crystalline defect is observed in the projection. Two section topographs are also presented (IIb, IIc). Figure 3IIb exhibits strong black contrasts associated to the edge of the pattern. As explained in section 2 , one can improve the resolution of the section topogram straight below the pattern edges by adjusting the position of the exit slot. The resulting photograph is presented in figure 3IIc. Just below the pattern edges, a new fringe due to a homogeneous elastic strain is seen [4]. Outside this perturbed region, the silicon wafer keeps its crystalline perfection.

In sequence III, numerous " point defects " occur in the sample. They are clearly seen in the projection (Fig. 3IIIa). The location of these defects is determined by recording section topograms (IIIb, c). The plates show that they are created at the poly $\mathrm{Si}-\mathrm{Si}$ interface and that they stay in the vicinity of the back-side. Moreover, strong black contrasts are still visible at the front-side below the edge patterns (IIIb). They conceal the elastic deformation at this spot. However, the local strain can be visualized by the technique described above (see Fig. 3IIIc). Nevertheless, the presence of Pendellösung fringes show that the bulk wafer keeps its crystalline quality.

In step IV, a degradation of long range order in the crystal is observed as indicated by the disappearance of the X-ray interference fringes in figures $3 I \mathrm{IVb}, \mathrm{c}$.

\section{Conclusion.}

Several conclusions can be drawn from the above observations :

- An elastic strain is induced straight below the edges of the film pattern. The other parts of the wafer are not perturbed.

- No defects are created at the back-surface as long as a nitride layer protects polysilicon from oxidation. If the nitride film is removed, point defects develop at the poly $\mathrm{Si}-\mathrm{Si}$ interface.

- Further physicochemical and heat treatments perturb the bulk silicon lattice.

\section{Acknowledgments.}

We are indebted to F. Martin, P. Jeuch and P. Guyon of LETI/MSC/CEA (Grenoble) for providing us with Si wafers at different stages of their processing and for many helpful suggestions and discussions. In addition, we wish to thank the G.C.I.S. for its financial support. 

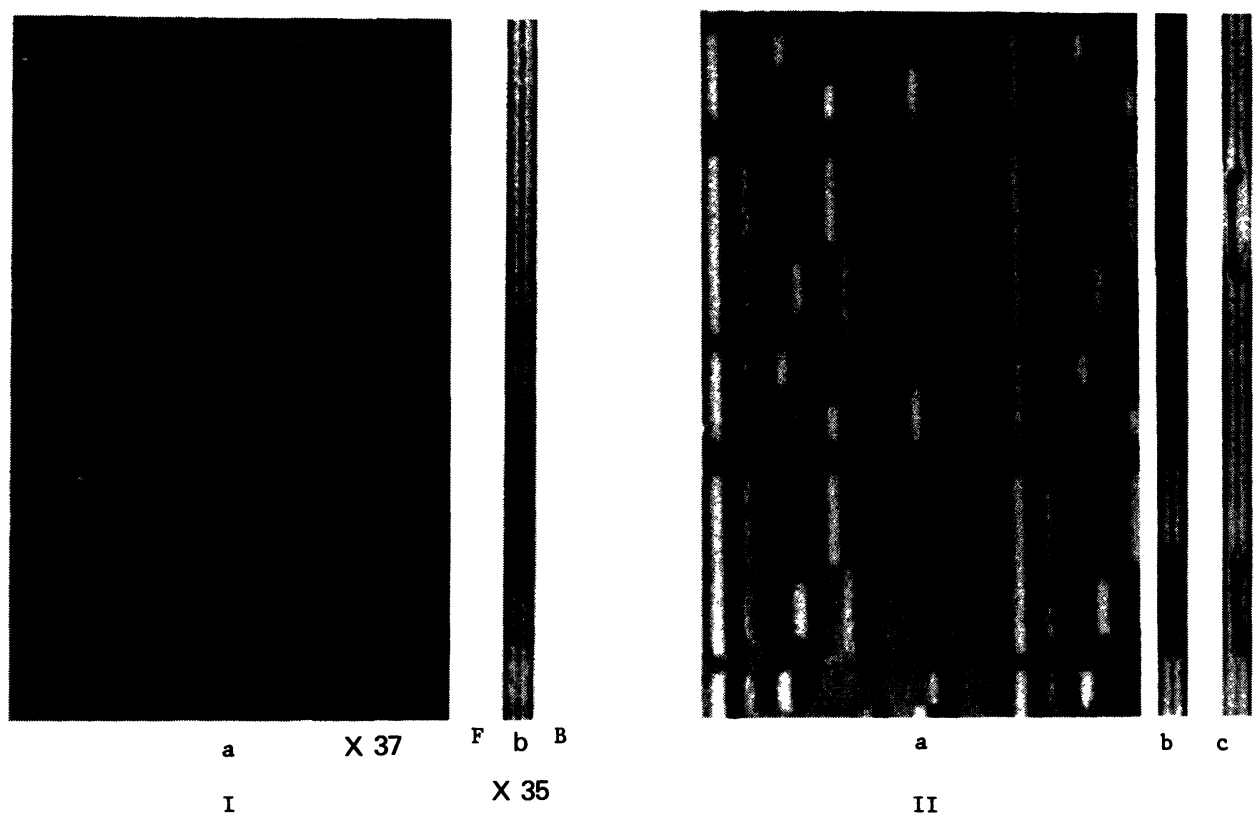

II
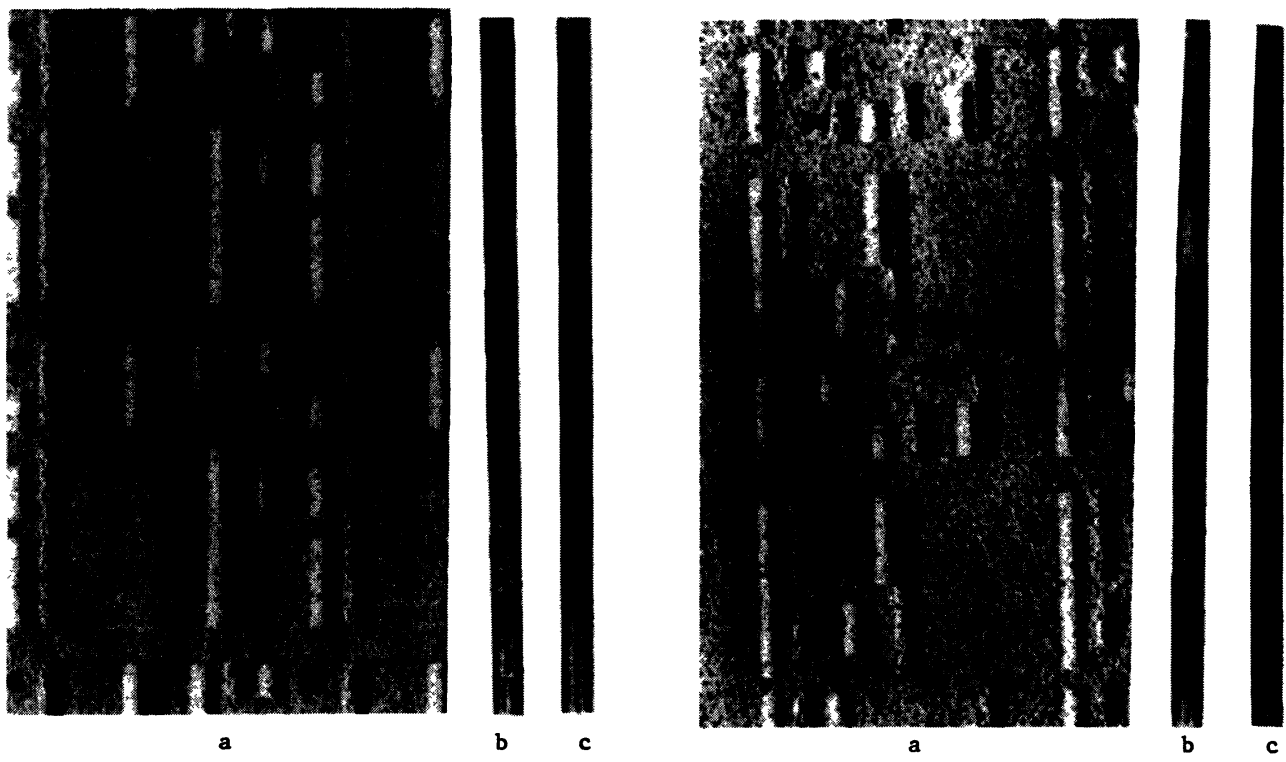

III

IV

Fig. 3. - X-ray topograms corresponding to the states I, II, III, IV of the processing -220 reflection $-\lambda \mathrm{K} \alpha_{1}$ Mo. a : projection topograms; b, c : section topograms ( $F$ : front-side, $B$ : back-side).

\section{References}

[1] Chen, M. C. and Silvestri, V. J., J. Electrochem. Soc. 129 (1982) 1294.

[2] Stacy, W. T., Arst, M. C., Ritz, K. N., De Groot, J. G. and Norcott, M. H., ECS Spring Meeting, Abstract $\mathrm{n}^{\circ}$ 310, San Francisco, mai 1983.

[3] Schnuttke, G. H. and Howard, J. K., J. Appl. Phys. 39, 3 (1968) 1581.

[4] Kato, N. and Patel, J. R., J. Appl. Phys. 44, 3 (1973) 965-977. 